OPEN ACCESS

Edited by:

Robert Gniadecki,

University of Alberta, Canada

Reviewed by:

Mitchell Stark,

University of Queensland, Australia

Thomas G. Salopek,

University of Alberta, Canada

*Correspondence:

Patrick Terheyden

patrick.terheyden@uksh.de

†These authors have contributed equally to this work

Specialty section:

This article was submitted to Dermatology,

a section of the journal

Frontiers in Medicine

Received: 23 July 2019

Accepted: 25 October 2019

Published: 17 December 2019

Citation:

Grätz V, Zillikens D, Busch H, Langan EA and Terheyden P (2019) Sequential Treatment With Targeted and Immune Checkpoint Therapy in

Patients With BRAF Positive

Metastatic Melanoma: The

Importance of Timing?

Front. Med. 6:257.

doi: 10.3389/fmed.2019.00257

\section{Sequential Treatment With Targeted and Immune Checkpoint Therapy in Patients With BRAF Positive Metastatic Melanoma: The Importance of Timing?}

\author{
Victoria Grätz ${ }^{1}$, Detlef Zillikens ${ }^{1}$, Hauke Busch ${ }^{2,3}$, Ewan A. Langan ${ }^{1,4 \dagger}$ and \\ Patrick Terheyden ${ }^{1 *+}$
}

\begin{abstract}
'Department of Dermatology, University of Lübeck, Lübeck, Germany, ${ }^{2}$ Lübeck Institute of Experimental Dermatology, University of Lübeck, Lübeck, Germany, ${ }^{3}$ Institute of Cardiogenetics, University of Lübeck, Lübeck, Germany,

${ }^{4}$ Dermatological Science, University of Manchester, Manchester, United Kingdom
\end{abstract}

Background: Immune checkpoint- and targeted therapy have dramatically improved the therapeutic landscape in the management of BRAF mutation positive metastatic melanoma. However, pending the results of clinical trials, not only is it currently unclear whether immune checkpoint- or targeted therapy should be commenced up front, but the optimal time for changing treatment, specifically to prevent resistance whilst maintaining disease control, is unknown.

Methods: We retrospectively identified eleven patients with BRAF V600 mutated metastatic melanoma who commenced targeted therapy between 11/2012 and 12/2017 in our center. In 5 cases the decision was made to "electively" switch to immune checkpoint therapy (elective group) following the development of a complete or partial response. In the remaining 6 cases the initial "reactive" switch was necessitated by disease progression or the development of intolerable side-effects (reactive group).

Results: Overall, the elective cohort had a more favorable course in terms of overall survival (1,003 vs. 827 days), and $80 \%$ of the patients remain alive, in contrast to $17 \%$ of the patients in the reactive group. However, it should be borne in mind that multiple switches due to disease progression were undertaken and this undoubtedly also impacted upon overall survival.

Conclusion: Elective switching from targeted to immune checkpoint therapy was associated with a better outcome in terms of survival, at least in everyday clinical practice. It remains unclear whether the choice of initial therapy confers long-term survival and disease-control advantages and this should be addressed in prospective studies.

Keywords: melanoma, sequential treatment, targeted therapy, immunotherapy, BRAF mutation 


\section{INTRODUCTION}

The therapeutic options for the management of metastatic melanoma in BRAF-mutated patients have improved dramatically with the development of targeted and immune checkpoint based therapies. The BRAF activating mutation is present in $40-50 \%$ of melanomas, providing an important therapeutic target that can be clinically exploited by inhibiting the MAPK/ERK signaling pathway (1). The combination of BRAF and MEK inhibition is associated with improved overall survival (OS) and may reduce the incidence of resistance $(2,3)$. Indeed, Schadendorf et al. reported that pooled analyses of clinical trials of dabrafenib and trametinib revealed a 3 year overall survival (OS) rate of $44 \%$ (4). Recently updated data revealed a 5 year OS of $34 \%$ (5). In patients with favorable prognostic factors, including a normal serum lactate dehydrogenase (LDH) level, the sum of lesion diameters $<66 \mathrm{~mm}$ and metastases in $<3$ organs, the 3 year progression free survival (PFS) rate was $42 \%$ (4). Similarly, Hauschild et al. reported 3 year OS rates of 53.3 $\%$ in patients with favorable prognostic features treated with cobimetinib and vemurafenib in a retrospective analysis of data from 4 randomized clinical trials (6). In fact, targeted therapy leads to a favorable tumor microenvironment in melanoma, with increased CD8 positive T cell infiltration and PD-L1 expression, suggesting a potential synergistic effect with immunotherapy (7).

Pending the results of ongoing clinical trials, the optimal firstline treatment strategy remains unclear and is likely to remain patient- and tumor-specific. Given the rapid response to targeted therapy, accompanied by a dramatic decrease in overall tumor load, the decision to commence targeted therapy in patients with BRAF V600 mutations may be favored in the context of symptomatic disease and the presence of adverse prognostic markers, including raised serum $\mathrm{LDH}$ concentrations, ECOG performance status $>1$, younger patients, and those with brain and/or metastases at multiple sites $(8,9)$. Typically, resistance to targeted therapy occurs after a median treatment time of 13 months. The use of immune checkpoint based therapies presents an important treatment option in the context of resistance to targeted therapies; the use of anti-programmed death protein (PD)- 1 therapies is associated with an impressive overall response and level of disease control, albeit with a slower onset of action, but potentially a more durable effect $(10,11)$. Furthermore, the published data points toward a more favorable outcome in patients with brain metastases treated with combined immune checkpoint therapy with nivolumab and ipilimumab (12). At present, the decision as to whether to first employ targetedor immune checkpoint therapy in patients with BRAF positive melanoma is reached after careful consideration of the overall disease burden, LDH levels, the presence of central nervous system metastases and clinician/individual patient preference. Several trials are currently examining the efficacy of sequenced targeted and immunotherapy (NCT02902029, NCT03235245) in order to establish whether sequential treatment represents a useful treatment strategy to deliver and sustain disease control.

Pending the results from these trials, we describe our clinical experience in 11 patients with melanoma stage IV, who were initially treated with targeted therapy and switched to immune checkpoint therapy (i) electively (based on partial or complete response and to prevent resistance) or (ii) in response to disease progression, in a sequential order.

\section{PATIENTS AND METHODS}

We retrospectively analyzed the clinical course of 11 patients with BRAF V600 mutation positive malignant melanoma who commenced targeted therapy between $11 / 2012$ and 12/2017 in our center (Figure 1). A partial or complete radiological response was required in order to justify electively switching treatment from targeted to immune therapy to prevent the development of resistance. When staging examinations (CT/MRI) revealed disease progression the treatment was switched from targeted to immune therapy in a reactive manner due to an inadequate treatment response. The retrospective analysis was approved by the University of Luebeck's ethics committee (19-117A). Graph Pad Prism (Version 8.0.2) was used for the survival analyses and survival curves were compared with log rank (Mantel-Cox) tests. A $p<0.05$ was considered significant.

\section{RESULTS}

\section{Elective Switching From Targeted to Immunotherapy Is Associated With Improved Overall Survival}

In order to ascertain the clinical course and calculate the overall survival of patients who were treated with sequential targeted therapy followed by immunotherapy a retrospective analysis of the electronic case notes was performed. Patients were retrospectively assigned to an "elective" or "reactive" cohort depending on whether therapy was switched electively on the basis of a radiological partial or complete response or reactively due to disease radiographic disease progression and/or intolerable side-effects (see Tables 1-3). There were no significant differences between the baseline characteristics of the groups in terms of age, baseline lactate dehydrogenase, and serum S100 concentrations.

As expected with two small cohorts, there was no significant difference in terms of the length of overall survival between the groups. However, it is worth noting that the clinical course in Patient 2 (reactive group) differed markedly from that of the other patients in the cohort. Not only did the patient initially receive monotherapy with $\mathrm{BRAF}$ inhibition, but the patient also received chemotherapy with dacarbazine prior to being switched to ipilimumab. The patient was only then switch to combined targeted therapy due to disease progression.

Interestingly, exclusion of the outlier patient and the patient who committed suicide in the reactive group revealed a significant $(p=0.01)$ difference in overall survival.

Moreover, the average length of overall survival in the elective group was 1,003 days compared to 827 days in the reactive group. At last follow up, $83 \%$ of the patients in the reactive cohort had died, including one patient who committed suicide whilst only one patient $(20 \%)$ in the elective group had died. 
A

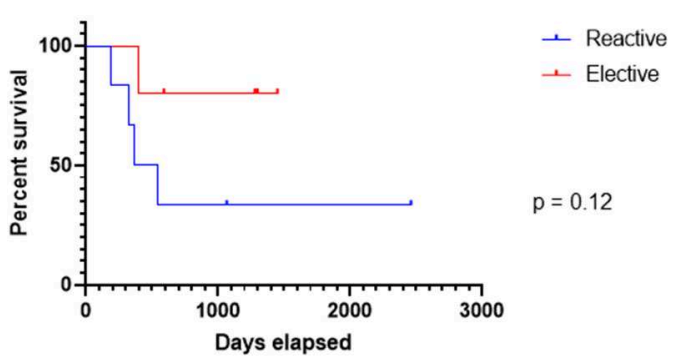

B

\section{Overall Survival}

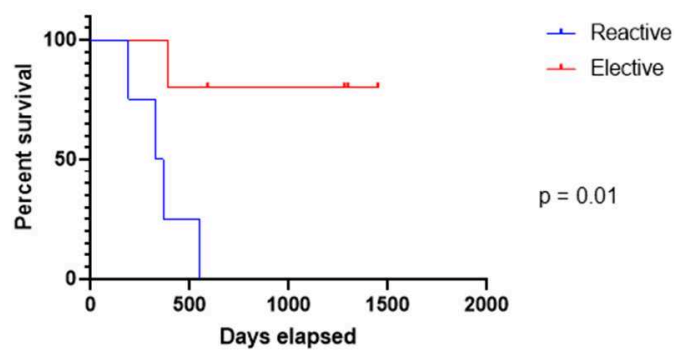

FIGURE 1 | Overall survival in the elective and reactive cohorts. Whilst there was no significant difference in overall survival between the cohorts (A), exclusion of the outlier patient, the only patient to have received chemotherapy prior to the switch from targeted to immunotherapy, and the patient who committed suicide, revealed a significant $(p=0.01)$ difference in overall survival $\mathbf{( B )}$.

\section{DISCUSSION}

An overall survival benefit of elective switching from targeted to immunotherapy could be demonstrated in 4 out of 5 cases, with a maximal OS of up to almost 4 years. In each of these patients the decision to switch from targeted therapy to immunotherapy was made electively at the time of complete or partial response, given the overall clinical response and to prevent the development of treatment resistance.

Initial treatment with targeted therapy may be favored in patients with a BRAF V600 mutation in the context of a large tumor burden and adverse prognostic factors (including increased $\mathrm{LDH}$ ) in whom rapid disease control is of paramount importance. Whether initial treatment with checkpoint immunotherapy in patients with BRAF mutations, provides any long-term and durable therapeutic advantages over targeted therapy remains the subject of intense investigation. As outlined by Luke et al. the decision to initiate targeted therapy may be favored when rapid disease control and/or immunepriming effects are required, whereas increased LDH and avoidance of resistance may favor initial checkpoint therapy (13).

Ackerman et al. analyzed the outcome of 274 patients treated with immunotherapy prior to $(n=32)$ or after $(n=242)$ BRAF inhibition. This retrospective study reported that prior treatment with targeted therapy did not negatively influence the response to subsequent immunotherapy with ipilimumab. However, outcomes for patients treated with ipilimumab following BRAF inhibition were poor (14). It should be noted that this was retrospective study and at the time the only licensed immunotherapy was monotherapy with ipilimumab. Aya et al. (8) failed to uncover any differences in overall survival in a small retrospective cohort study specifically comparing targeted then immune therapy and vice versa. However, results from prospective trials examining sequential therapy, e.g., NCT02224781 or SECOMBIT (NCT02631447) with additional checkpoint inhibitors, are eagerly anticipated.

The combination of targeted therapy and immunotherapy, either in a parallel or sequential manner, could theoretically lead to enhanced anti-tumor responses, reflected in durable responses and prolonged survival. In fact, the length of response
TABLE 1 | Patient characteristics in both the elective and reactive cohorts.

\begin{tabular}{|c|c|c|c|}
\hline $\begin{array}{l}\text { Patient } \\
\text { characteristics }\end{array}$ & $\begin{array}{l}\text { Elective } \\
\text { group }\end{array}$ & $\begin{array}{l}\text { Reactive } \\
\text { group }\end{array}$ & $p$ value \\
\hline \multicolumn{4}{|l|}{ Sex } \\
\hline Male & 4 & 5 & \\
\hline Female & 1 & 1 & \\
\hline \multicolumn{4}{|l|}{ Age } \\
\hline Range (years) & $39-67$ & $24-75$ & \\
\hline Mean & 51.4 & 54.7 & 0.75 \\
\hline \multicolumn{4}{|l|}{ Overall survival } \\
\hline Range (days) & $393-1451$ & $192-2462$ & \\
\hline Mean & 1002.8 & 827.2 & 0.69 \\
\hline \multicolumn{4}{|c|}{ Primary tumor site } \\
\hline $\begin{array}{l}\text { Unknown } \\
\text { primary }\end{array}$ & 2 & 0 & \\
\hline Back & 1 & 1 & \\
\hline Leg & 2 & 3 & \\
\hline Head/Neck & 0 & 2 & \\
\hline $\begin{array}{l}\text { Mean S100 prior } \\
\text { to targeted } \\
\text { therapy } \mu \mathrm{g} / \mathrm{l}\end{array}$ & 0.41 & 1.06 & 0.30 \\
\hline $\begin{array}{l}\text { Mean LDH prior } \\
\text { to targeted } \\
\text { therapy U/I }\end{array}$ & 244.8 & 328.5 & 0.33 \\
\hline
\end{tabular}

to BRAF/MEK inhibition may be key. For example, Ascierto et al. reported that in patients who responded to BRAF/MEK inhibition for over 6 months, the overall response rate to subsequent anti-PD1 therapy was $34 \%$ (15). In contrast, when patients benefits for $<6$ months, the overall response rate to subsequent anti-PD1 therapy was only $15 \%$. This sits well with the evidence that BRAF inhibition can improve the efficacy of PD-1 blockade via changes in the tumor microenvironment $(10,15,16)$. In fact, BRAF/MAPK targeted therapy can alter the immune environment within 2 weeks (16), resulting in elevated PD-L1 expression for up to 3 months (17). It is however important to bear in mind that these changes may be temporary, perhaps opening up a therapeutic window in which the potential benefits from switching to immune therapy 
TABLE 2 | Switching from targeted to immunotherapy when a partial or complete response is achieved.

\begin{tabular}{|c|c|c|c|c|c|c|c|c|c|c|c|c|c|c|c|c|c|c|c|}
\hline Sex & Age & $\begin{array}{l}\text { Primary } \\
\text { tumor }\end{array}$ & $\mathrm{R} \times 1$ & $\begin{array}{c}S 100 \\
\text { Normal } \\
\text { value }< \\
0.11 \mu \mathrm{g} / \mathrm{l}\end{array}$ & $\begin{array}{l}\text { LDH } \\
\text { Normal } \\
\text { value < } \\
250 \mathrm{U} / \mathrm{l}\end{array}$ & $\begin{array}{l}\text { Pre-Switch } \\
\text { response }\end{array}$ & $\begin{array}{l}\text { Duration } \\
\text { (days) }\end{array}$ & $\mathrm{Rx} 2$ & $S 1002$ & LDH 2 & Duration 2 & $\mathrm{R} \times 3$ & S1003 & LDH 3 & Duration 3 & $\mathrm{Rx} 4$ & S100 4 & LDH 4 & $\begin{array}{l}\text { Duration } \\
\quad 4\end{array}$ \\
\hline \multirow[t]{7}{*}{ M } & 50 & MUP & Vem/Cobi & 0.09 & 207 & PR & 152 & $\begin{array}{l}\text { Nivolumab/ } \\
\text { Ipilimumab }\end{array}$ & 0.08 & 302 & 433 & Vem/Cobi & 0.99 & 273 & 356 & $\begin{array}{l}\text { Nivolumab } 3 \\
\mathrm{mg} / \mathrm{kg} \times 1\end{array}$ & 0.11 & 310 & 215 \\
\hline & & & & & & & & 4 Cycles & & & & Thrombocytopenia & & & & $\begin{array}{l}\text { Nivolumab } \\
480 \mathrm{mg}\end{array}$ & & & \\
\hline & & & & & & & & $\begin{array}{l}\text { Autoimmune hepatits } \\
\text { grade } 3\end{array}$ & & & & $\begin{array}{l}\text { Prednisolone } 1 \\
\mathrm{mg} / \mathrm{kg}\end{array}$ & & & & 7 Cycles & & & \\
\hline & & & & & & & & Prednisolone $2 \mathrm{mg} / \mathrm{kg}$ & & & & & & & & & & & \\
\hline & & & & & & & & Cellcept $1 \mathrm{~g}$ b.d. & & & & & & & & & & & \\
\hline & & & & & & & & $\begin{array}{l}\text { Nivolumab } 3 \text { mg/kg } \\
\text { monotherapy }\end{array}$ & & & & & & & & & & & \\
\hline & & & & & & & & 3 Cycles & & & & & & & & & & & \\
\hline \multirow[t]{6}{*}{$\mathrm{F}$} & 43 & $\begin{array}{l}\text { Nodular } \\
\text { Melanoma }\end{array}$ & $\mathrm{Dab} /$ Tram & 0.18 & 179 & CR & 210 & $\begin{array}{l}\text { Nivolumab/ } \\
\text { Ipilimumab }\end{array}$ & 0.05 & 215 & 43 & $\mathrm{Dab} / \mathrm{ram}$ & 0.07 & 189 & 80 & $\begin{array}{l}\text { Nivolumab } 3 \\
\mathrm{mg} / \mathrm{kg}\end{array}$ & 0.05 & 183 & 107 \\
\hline & & Left thigh & & & & & & 1 Cycle & & & & & & & & 8 Cycles & & & \\
\hline & & & & & & & & $\begin{array}{l}\text { Autoimmune } \\
\text { thyroiditis grade } 3\end{array}$ & & & & & & & & Radiotherapy & & & \\
\hline & & & & & & & & Mumps infection & & & & & & & & & & & \\
\hline & & & & & & & & $\begin{array}{l}\text { Exzision of a } \\
\text { subcutaneous }\end{array}$ & & & & & & & & & & & \\
\hline & & & & & & & & metastasis & & & & & & & & & & & \\
\hline \multirow[t]{2}{*}{ M } & 67 & Melanoma & $\begin{array}{l}\operatorname{Vem}(2 \times \\
960 \mathrm{mg})\end{array}$ & 1.43 & 407 & PR & 54 & Ipilimumab 3 mg/kg & 0.05 & 181 & 78 & $\mathrm{Dab} /$ Tram & 1.66 & 343 & 196 & $\begin{array}{l}\text { Nivolumab } 3 \\
\mathrm{mg} / \mathrm{kg}\end{array}$ & 0.41 & 308 & 30 \\
\hline & & Left thigh & & & & & & 4 Cycles & & & & & & & & 2 Cycles & & & \\
\hline \multirow[t]{8}{*}{ M } & 39 & SSM & Vem/Cobi & 0.29 & 262 & PR & 303 & $\begin{array}{l}\text { Nivolumab/ } \\
\text { Ipilimumab }\end{array}$ & 0.05 & 327 & 54 & Vem/Cobi & 0.04 & 204 & 161 & $\begin{array}{l}\text { Pembrolizumab } \\
2 \mathrm{mg} / \mathrm{kg}\end{array}$ & 0.05 & 312 & 168 \\
\hline & & Back & & & & & & 4 Cycles & & & & & & & & 8 Cycles & & & \\
\hline & & & & & & & & $\begin{array}{l}\text { Autoimmune } \\
\text { thyroiditis grade } 3\end{array}$ & & & & & & & & Radiotherapy & & & \\
\hline & & & & & & & & $\begin{array}{l}\text { Autoimmune hepatitis } \\
\text { grade } 2\end{array}$ & & & & & & & & & & & \\
\hline & & & & & & & & Prednisolone $1 \mathrm{mg} / \mathrm{kg}$ & & & & & & & & & & & \\
\hline & & & & & & & & Neutropenia & & & & & & & & & & & \\
\hline & & & & & & & & $\begin{array}{l}\text { Nivolumab } 3 \text { mg/kg } \\
\text { monotherapy }\end{array}$ & & & & & & & & & & & \\
\hline & & & & & & & & 6 Cycles & & & & & & & & & & & \\
\hline \multirow[t]{4}{*}{ M } & 58 & MUP & Vem/Cobi & 0.06 & 169 & $C R$ & 188 & Nivolumab/pilimumab & 0.09 & 207 & 96 & Enco/Bini & 0.07 & 193 & 293 & & & & \\
\hline & & & & & & & & 4 Cycles & & & & Radiotherapy & & & & & & & \\
\hline & & & & & & & & Colitis grade 3 & & & & & & & & & & & \\
\hline & & & & & & & & Prednisolone $1 \mathrm{mg} / \mathrm{kg}$ & & & & & & & & & & & \\
\hline
\end{tabular}


TABLE 2 | Continued

Sex Age $\begin{aligned} & \text { Prima } \\ & \text { tumo }\end{aligned}$

M $50 \quad$ MUP

S100 5 LDH 5 Duration 5

Rx 6

S100 6

LDH 6 Duratio

6

Rx 7

51007

LDH 7 Duration 7

$\begin{array}{llll}\text { Enco/Bini } \quad 0.30 \quad 233 & 271\end{array}$

$\begin{array}{lccccc}\begin{array}{l}\text { Nodular } \\ \text { Melanoma } \\ \text { Left thigh }\end{array} & \text { Vem/Cobi } & 0.08 & 178 & 10 & \begin{array}{c}\text { Ipilimumab 3 } \\ \mathrm{mg} / \mathrm{kg} \\ \text { Nivolumab 1 } \\ \end{array} \\ & \text { Sepsis } & & & & \mathrm{mg} / \mathrm{kg} \\ & \begin{array}{c}\text { Drug- } \\ \text { induced } \\ \text { exanthem }\end{array} & & & & 4 \text { Cycles } \\ & & & & \end{array}$

M

67 Melanoma

Left thigh

39 SSM

Back

Nilimumab/

Nivolumab
2 Cycles

Pembrolizumab

8 Cycles 2

$\mathrm{mg} / \mathrm{kg}$

Pembrolizumab

$200 \mathrm{mg}$

fortnightly

Pembrolizumab

$400 \mathrm{mg}$

2 Cycles in 3

week

Radiotherapy

$\begin{array}{cclllll}0.08 \quad 172 \quad 54 \quad & \text { Dab//ram } & 0.44 & 174 & 655 & 1280-\text { Alive } \\ & \text { Sarcoidosis } \\ & \text { Cellultis } \\ & \\ & \text { Exzision of a } \\ \text { subcutaneous } \\ \text { metastasis }\end{array}$

393 - Dead

1451 - Alive

591 - Alive

The clinical course in patients electively switched from targeted to immune therapy based on the clinical response.

Dabra/Tram, Dabrafenib/Trametinib; Enco/Bini, Encorafenib; Binimetinib; LDH, lactate dehydrogenase; MUP, melanoma of unknown primary; SSM, superficial spreading melanoma; CR, complete response; PD, progressive disease; PR, partial response; Vem/Cobi; Vemurafenib/Cobimetinib. 
TABLE 3 | Switching from targeted to immunotherapy due to disease progression or intolerable side-effects

\begin{tabular}{|c|c|c|c|c|c|c|c|c|c|c|c|c|c|c|c|c|c|c|c|}
\hline Sex & Age & Primary tumor & $\mathrm{Rx} 1$ & S100 1 & LDH 1 & $\begin{array}{l}\text { Pre-Switch } \\
\text { response }\end{array}$ & Duration & $\mathrm{R} \times 2$ & S100 2 & LDH 2 & Duration 2 & $\mathrm{R} \times 3$ & S100 3 & LDH 3 & $\begin{array}{l}\text { Duration } \\
\quad 3\end{array}$ & $\mathrm{Rx} 4$ & S100 4 & LDH 4 & $\begin{array}{l}\text { Duration } \\
4\end{array}$ \\
\hline \multirow[t]{5}{*}{ M } & 75 & SSM & $\mathrm{Dab} /$ Tram & 0.37 & 267 & $\begin{array}{l}\text { Therapy changed } \\
\text { due to side effects: }\end{array}$ & 85 & Vem/Cobi & 0.17 & 371 & 219 & Nivolumab & 0.06 & 203 & 91 & $\begin{array}{l}\text { Nivolumab/ } \\
\text { Ipilimumab }\end{array}$ & 0.11 & 223 & 115 \\
\hline & & Right Thigh & & & & & & & & & & $\begin{array}{l}3 \mathrm{mg} / \mathrm{kg} 7 \\
\text { Cycles }\end{array}$ & & & & 2 Cycles & & & \\
\hline & & & & & & Recurrent Pyrexia & & & & & & & & & & Radiotherapy & & & \\
\hline & & & & & & & & & & & & & & & & Colitis Grade 3 & & & \\
\hline & & & & & & & & & & & & & & & & $\begin{array}{l}\text { Prednisolone } 1 \\
\mathrm{mg} / \mathrm{kg}\end{array}$ & & & \\
\hline \multirow[t]{3}{*}{$\mathrm{F}$} & 45 & Nodular Melanoma & $\begin{array}{l}\text { Dab then } \\
\text { Vem }\end{array}$ & 1.17 & 258 & $\begin{array}{l}\text { Therapy changed } \\
\text { due to side effects: }\end{array}$ & 101 & Dacarbazine & 0.156 & 187 & 71 & Ipilimumab & 3.03 & 383 & 79 & $\begin{array}{l}\text { Nivolumab } \\
3 \mathrm{mg} / \mathrm{kg}\end{array}$ & 4.11 & 366 & 196 \\
\hline & & Back & & & & & & $\begin{array}{l}250 \mathrm{mg} / \mathrm{m}^{2} \text { over } 5 \\
\text { days }\end{array}$ & & & & $3 \mathrm{mg} / \mathrm{kg}$ & & & & 14 Cycles & & & \\
\hline & & & & & & Retinitis Serosa & & 3 Cycles & & & & 4 Cycles & & & & Radiotherapy & & & \\
\hline \multirow[t]{3}{*}{ M } & 24 & SSM & Enco/Bini & 3.13 & 575 & PD & 224 & $\begin{array}{l}\text { Nivolumab/ } \\
\text { Ipilimumab }\end{array}$ & 0.64 & 420 & 23 & Dab/Tram & 2.51 & 755 & 32 & $\begin{array}{l}\text { Dacarbazine } 1000 \\
\mathrm{mg} / \mathrm{m}^{2}\end{array}$ & 3.98 & 620 & \\
\hline & & Back & & & & & & 2 Cycles & & & & Radiotherapy & & & & 2 Cycles & & & \\
\hline & & & & & & & & Radiotherapy & & & & & & & & & & & \\
\hline \multirow[t]{3}{*}{ M } & 54 & Nodular Melanoma & $\mathrm{Dab} /$ Tram & 0.12 & 214 & PD & 62 & $\begin{array}{l}\text { Nivolumab } 3 \\
\mathrm{mg} / \mathrm{kg}\end{array}$ & 0.16 & 308 & & & & & & & & & \\
\hline & & Back & & & & & & 5 Cycles & & & & & & & & & & & \\
\hline & & & & & & & & Radiotherapy & & & & & & & & & & & \\
\hline \multirow[t]{2}{*}{ M } & 56 & Nodular Melanoma & $\mathrm{Dab} /$ Tram & $\mathrm{N} / \mathrm{A}$ & 467 & PD & 318 & $\begin{array}{l}\text { Nivolumab/ } \\
\text { Ipilimumab }\end{array}$ & 0.03 & 195 & & & & & & & & & \\
\hline & & Neck & & & & & & & & & & & & & & & & & \\
\hline \multirow[t]{3}{*}{$\mathrm{M}^{*}$} & 74 & Nodular Melanoma & Enco/Bini & 0.53 & 190 & PD & 284 & Pembrolizumab & 0.03 & 179 & 203 & Cobi/Nem & 173 & 0.04 & 69 & Pembrolizumab & 0.04 & 168 & 456 \\
\hline & & Right ear & & & & & & 10 Cycles & & & & Surgery & & & & 20 Cycles & & & \\
\hline & & & & & & & & & & & & Radiotherapy & & & & & & & \\
\hline
\end{tabular}


TABLE 3 | Continued

Sex Age Primary tumor

Rx 5 S100 5 LDH 5 Duration 5

$\mathrm{Rx} 6 \quad \mathbf{S 1 0 0 6}$

LDH 6 Duration

Rx 8

Rx 11 OS (days)/Status

M $\quad 75$ SSM Right Thigh

F 45 Nodular Melanoma Vem

$634 \quad 707$

Ipilimumab 3197
$\mathrm{mg} / \mathrm{kg}$
2 Cycles
Radiotherapy

0.06

92 Nivolumab Vem/

$\begin{array}{cc}\text { Nivolumab Vem/ } & \begin{array}{c}\text { Ipilimumab/ } 2462 \text { - Alive } \\ \text { Cobi } \\ \text { Nivolumab } \\ 3 \mathrm{mg} / \mathrm{kg} \text { and } \\ 480 \mathrm{mg}\end{array} \\ \begin{array}{c}1 \mathrm{mg} / \mathrm{kg} \\ 2 \text { Cycles }\end{array} & 4 \text { Cycles } \\ & \end{array}$

M 24 SSM

Vem/Cobi

Radiotherapy

Back

M 54 Nodular Melanoma

192 - Dead

Back

M 56 Nodular Melanoma

Neck

M $^{*} 74$ Nodular Melanoma

Right ear

The clinical course is detailed in patients switched from targeted to immune therapy due to disease progression or intolerable treatment related side-effects.

*The patient committed suicide during the study period.

Dabra/Tram, Dabrafenib/Trametinib; Enco/Bini, Encorafenib; Binimetinib; LDH, lactate dehydrogenase; MUP, melanoma of unknown primary; SSM, superficial spreading melanoma; CR, complete response; PD, progressive disease; $P R$, partial response; Vem/Cobi; Vemurafenib/Cobimetinib. 
can be harnessed. Other authors have reported complete and durable remission using finite courses of BRAF inhibition following failure to respond to immunotherapy (18). However, these observations are based on small case series. Most recently concern has been raised about the tolerability and side effect profile of BRAF/MEK inhibition after anti-PD-1 therapy (19). Indeed, the authors speculated that the increased incidence of treatment interruptions may impact upon the rates of OS.

In contrast to this observation (19), it has been reported that initial anti-PD-1 therapy in patients with BRAF mutations may be associated with improved overall survival when compared to patients initially treated with targeted therapy (20). Despite being a multi-centric analysis, these data were again retrospective.

Overall, we witnessed fewer treatment related toxicities in the reactive switch group. Given that the development of toxicities is associated with an improved response to immunotherapy (21), the lack of side-effects correlated well with the lack of disease control and overall poorer prognosis.

A major limitation of our case series is its retrospective nature. Decisions on which targeted therapies and which immune checkpoint therapies were administered (anti-PD-1 monotherapy vs. combined anti-PD- 1 and anti-CTLA- 4 therapy) were taken by the multi-disciplinary tumor board. These decisions were based on tumor factors (tumor activity and overall disease burden) and patient factors (including relevant co-morbidities). Whilst the various treatment combinations and retrospective nature of the analysis could be interpreted as weaknesses, it should nevertheless be borne in mind that the data reflect the "real-life" clinical management of metastatic melanoma.

Summarizing the results of sequential therapy in our cohort, it is reasonable to conclude that switching between targeted and immune checkpoint therapy, and vice versa, which can be complemented by radiotherapy of brain metastases, may be associated with improved long-term survival, even in patients with an extensive disease burden. This treatment strategy may be useful strategy to prevent the development of resistance to MEK/BRAF inhibition. However, given the historical context of our retrospective analysis which meant that all patients were initially treated with targeted therapy, no

\section{REFERENCES}

1. Kong BY, Carlino MS, Menzies, AM. Biology and treatment of BRAF mutant metastatic melanoma. Melanoma Manag. (2016) 3:33-45. doi: $10.2217 / \mathrm{mmt} .15 .38$

2. Dummer R, Schadendorf D, Ascierto PA, Larkin J, Lebbé C, Hauschild A. Integrating first-line treatment options into clinical practice: what's new in advanced melanoma? Melanoma Res. (2015) 25:461-9. doi: 10.1097/CMR.00000000000 00200

3. Broman KK, Dossett LA, Sun J, Eroglu Z, Zager JS. Update on BRAF and MEK inhibition for treatment of melanoma in metastatic, unresectable, and adjuvant settings. Expert Opin Drug Saf. (2019) 18:381-92. doi: 10.1080/14740338.2019.1607289 conclusions can be drawn on which upfront treatment strategy is best.

In the absence of evidence-based clinical data, the decision to switch between targeted and immune checkpoint based therapy and the importance of timing in terms of switching treatment modality remains a clinical conundrum (22). Indeed, with increasing rates and duration of overall survival, the specific contribution of the upfront therapy and therapy switches to any survival benefit is difficult to ascertain. Moreover, progressionfree survival is also of limited benefit to measure treatment efficacy, given that targeted therapy treatment may be switched to immune therapy "electively" before tumor progression to prevent the development of resistance. Identifying the optimal time to switch therapy, depending on the duration and extent of the response to treatment, remains to be determined definitively. However, the publication of non-selected real-life clinical data reporting the long-term efficacy and tolerability of sequential therapy may help inform clinical practice until the definitive results from the on-going, prospective, and multi-center clinical trials are available.

\section{DATA AVAILABILITY STATEMENT}

The datasets generated for this study are available on request to the corresponding author.

\section{ETHICS STATEMENT}

The study was reviewed and approved by University of Lübeck Ethics Committee (19-117A).

\section{AUTHOR CONTRIBUTIONS}

VG provided the patient details. VG, EL, and PT wrote the manuscript. HB provided biostatisical advice. All co-authors critically reviewed and edited the manuscript.

\section{ACKNOWLEDGMENTS}

We would like to thank the patients whose clinical courses are detailed in the manuscript.
4. Schadendorf D, Long GV, Stroiakovski D, Karaszewska B, Hauschild A, Levchenko E, et al. Three-year pooled analysis of factors associated with clinical outcomes across dabrafenib and trametinib combination therapy phase 3 randomised trials. Eur J Cancer. (2017) 82:45-55. doi: 10.1016/j.ejca.2017.05.033

5. Robert C, Grob JJ, Stroyakovskiy D, Karaszewska B, Hauschild A, Levchenko E, et al. Five-year outcomes with dabrafenib plus trametinib in metastatic melanoma. N Engl J Med. (2019) 381:626-36. doi: 10.1056/NEJMoa1904059

6. Hauschild A, Larkin J, Ribas A, Dréno B, Flaherty KT, Ascierto PA, et al. Modeled prognostic subgroups for survival and treatment outcomes in BRAF V600-mutated metastatic melanoma: pooled analysis of 4 randomized clinical trials. JAMA Oncol. (2018) 4:1382-8. doi: 10.1001/jamaoncol.2018.2668

7. Frederick DT, Piris A, Cogdill AP, Cooper ZA, Lezcano C, Ferrone $\mathrm{CR}$, et al. BRAF inhibition is associated with enhanced melanoma 
antigen expression and a more favorable tumor microenvironment in patients with metastatic melanoma. Clin Cancer Res. (2013) 19:1225-31. doi: 10.1158/1078-0432.CCR-12-1630

8. Aya F, Fernandez-Martinez A, Gaba L, Victoria I, Tosca M, Pineda E, et al. Sequential treatment with immunotherapy and BRAF inhibitors in BRAF-mutant advanced melanoma. Clin Transl Oncol. (2017) 19:119-24. doi: 10.1007/s12094-016-1514-0

9. Ratterman M, Hallmeyer S, Richards J. Sequencing of new and old therapies for metastatic melanoma. Curr Treat Options Oncol. (2016) 17:52. doi: 10.1007/s11864-016-0427-z

10. Karachaliou N, Gonzalez-Cao M, Sosa A, Berenguer J, Bracht JWP, Ito $\mathrm{M}$, et al. The combination of checkpoint immunotherapy and targeted therapy in cancer. Ann Transl Med. (2017) 5:388. doi: 10.21037/atm.20 17.06.47

11. Ribas A, and Wolchok, JD. Cancer immunotherapy using checkpoint blockade. Science. (2018) 359:1350-5. doi: 10.1126/science. aar4060

12. Long GV, Atkinson V, Lo S, Sandhu S, Guminski AD, Brown MP, et al. Combination nivolumab and ipilimumab or nivolumab alone in melanoma brain metastases: a multicentre randomised phase 2 study. Lancet Oncol. (2018) 19:672-81. doi: 10.1016/S1470-2045(18)30139-6

13. Luke JJ, Flaherty KT, Ribas A, Long GV. Targeted agents and immunotherapies: optimizing outcomes in melanoma. Nat Rev Clin Oncol. (2017) 14:463-82. doi: 10.1038/nrclinonc.2017.43

14. Ackerman A, Klein O, McDermott DF, Wang W, Ibrahim N, Lawrence DP. Outcomes of patients with metastatic melanoma treated with immunotherapy prior to or after BRAF inhibitors. Cancer. (2014) 120:1695-701. doi: 10.1002/cncr.28620

15. Ascierto PA, Agarwala S, Botti G, Cesano A, Ciliberto G, Davies MA. Future perspectives in melanoma research: meeting report from the "Melanoma Bridge”. Napoli, December 1st-4th 2015. J Transl Med. (2016) 14:313. doi: 10.1186/s12967-016-1070-y

16. Reddy SM, Reuben A, and Wargo, JA. Influences of BRAF inhibitors on the immune microenvironment and the rationale for combined molecular and immune targeted therapy. Curr Oncol Rep. (2016) 18:42. doi: 10.1007/s11912-016-0531-Z

17. Jiang X, Zhou J, Giobbie-Hurder A, Wargo J, Hodi FS. The activation of MAPK in melanoma cells resistant to BRAF inhibition promotes PD-L1 expression that is reversible by MEK and PI3K inhibition. Clin Cancer Res. (2013) 19:598-609. doi: 10.1158/1078-0432.CCR-12-2731
18. Wyluda EJ, Cheng J, Schell TD, Haley JS, Mallon C, Neves RI, et al. Durable complete responses off all treatment in patients with metastatic malignant melanoma after sequential immunotherapy followed by a finite course of BRAF inhibitor therapy. Cancer Biol Ther. (2015) 16:662-70. doi: 10.1080/15384047.2015.1026507

19. Saab KR, Mooradian MJ, Wang DY, Chon J, Xia CY, Bialczak A, et al. olerance and efficacy of BRAF plus MEK inhibition in patients with melanoma who previously have received programmed cell death protein 1-based therapy. Cancer. (2019) 125:884-91. doi: 10.1002/cncr.31889

20. Schilling B, Martens A, Geukes Foppen MH, Gebhardt C, Hassel JC, Rozeman EA, et al. First-line therapy-stratified survival in BRAF-mutant melanoma: a retrospective multicenter analysis. Cancer Immunol Immunother. (2019) 68:765-72. doi: 10.1007/s00262-019-02311-1

21. Schadendorf D, Wolchok JD, Hodi FS, Chiarion-Sileni V, Gonzalez R, Rutkowski P, et al. Efficacy and safety outcomes in patients with advanced melanoma who discontinued treatment with nivolumab and ipilimumab because of adverse events: a pooled analysis of randomized phase II and III trials. J Clin Oncol. (2017) 35:3807-14. doi: 10.1200/JCO.2017.73.2289

22. Pavlick AC, Fecher L, Ascierto PA, Sullivan RJ. Frontline therapy for BRAF-mutated metastatic melanoma: how do you choose, and is there one correct answer? Am Soc Clin Oncol Educ Book. (2019) 39:564-71. doi: 10.1200/EDBK_243071

Conflict of Interest: EL has received travel support (Curevec, Novartis) and speaker's honoraria (Novartis) and also participated in advisory boards from Novartis. PT has received speaker's honoraria from BMS, Novartis, and Roche, consultant's honoraria from BMS, Merck, Novartis, Sanofi, and Roche, and travel support from BMS, Pierre-Fabre and Roche.

The remaining authors declare that the research was conducted in the absence of any commercial or financial relationships that could be construed as a potential conflict of interest.

Copyright () 2019 Grätz, Zillikens, Busch, Langan and Terheyden. This is an openaccess article distributed under the terms of the Creative Commons Attribution License (CC BY). The use, distribution or reproduction in other forums is permitted, provided the original author(s) and the copyright owner(s) are credited and that the original publication in this journal is cited, in accordance with accepted academic practice. No use, distribution or reproduction is permitted which does not comply with these terms. 